\title{
Effect of friction stir welding parameters on microstructure and mechanical properties of DSS-Cu joints
}

\author{
V. Shokri ${ }^{\mathrm{a}, *}$, A. Sadeghi ${ }^{\mathrm{b}}$, M.H. Sadeghi ${ }^{\mathrm{a}}$ \\ a Department of Mechanical Engineering, Tarbiat Modarres University, Tehran, Iran \\ b School of Mechanical Engineering, College of Engineering, University of Tehran, Tehran, Iran
}

\section{A R T I C L E I N F O}

\section{Keywords:}

Friction stir welding

Dissimilar joints

Duplex stainless steel/Copper alloy

\begin{abstract}
A B S T R A C T
Dissimilar joining of copper to duplex stainless steel (DSS) is challenging at high temperatures of fusion welding owing to the large difference in physical properties of the base metals. To reduce negative effects of welding at high temperatures, solid state welding at lower temperatures has been proposed. To study different effects of welding parameters (rotation speed, travel speed and tool offset) on weld zone microstructure and mechanical properties butt joints of a copper alloy and duplex stainless steel (DSS) were produced by friction stir welding (FSW). It has been found that heat input generated by the interaction of different welding conditions has a significant effect on the formation of a brittle intermetallic at the interface and eventually the final mechanical properties. At low heat inputs, mixing of the two sides is insufficient and metallurgical bonding is weak; while at high heat inputs, the thickness of the formed intermetallic is too thick which causes stress concentration at the interface and premature failure. An optimum welding condition was found (rotation speed of $1200 \mathrm{rpm}$, travel speed of $30 \mathrm{~mm} / \mathrm{min}$ and tool offset of $0.5 \mathrm{~mm}$ ) which almost reached the mechanical properties of the $\mathrm{Cu}$-alloy monolayer.
\end{abstract}

\section{Introduction}

To utilize the high thermal conductivity of copper and the high strength and corrosion resistance of duplex stainless steel in industrial assemblies, joining these dissimilar metals becomes technically important. Owing to the large difference between the physical properties of copper and steel, fusion welding would not be appropriate. For such combinations, lower temperature solid state joining techniques such as diffusion bonding and friction welding have received more attention [1-3]. As a variant of friction welding, friction stir welding (FSW) provides the opportunity of welding components with relatively flat geometry at high productivity. In FSW, the material is not melted and a third body tool is used to join the two facing surfaces. As the tool rotates, the friction between the tool shoulder and the workpiece generates sufficient heat to plasticize the material beneath the tool shoulder. The rotating tool pin moves the plasticized material from the front to the back of the weld line which results in joining between the butted plates. FSW is widely used for light alloys ( $\mathrm{Al}[2,4,5], \mathrm{Mg}[6]$ and $\mathrm{Ti}$ [7]), Cu-based alloys [8], steels [9] and dissimilar metals (Al/Mg [10-12], Al/Steel [13-15], Al/Cu [16-19], Al/Bronze [20] and duplex stainless steel (DSS)/low alloy steel [21]). So far, there are no experimental reports on FSW of DSS and Cu alloys. Having a 50\% ferrite and 50\% austenite microstructure, DSS provides a desirable combination of strength, ductility and corrosion resistance. In DSS, the $\sigma$-phase $(\mathrm{Fe}-\mathrm{Cr})$ is the most prominent intermetallic which appears between 600 and $1000{ }^{\circ} \mathrm{C}$ [22]. The $\sigma$-phase has adverse effects on the mechanical properties and corrosion resistance [23] and has been previously observed in welding and heat affected zones [24].

Joining of DSS to copper is generally difficult due to differences between their physical and chemical properties. Both alloys have incomparable melting points, thermal conductivities, the coefficient of linear expansions and heat capacities. The differences in physical properties are listed in Table 1.

As shown in Table 1, based on the large difference between the physical properties, achieving a strong joint between DSS and copper would be very difficult by common fusion welding techniques. However, in the FSW process, local melting of base metals could be avoided by precise control of welding parameters. Such parameters include tool rotation, traverse speed and tool offset which directly affect the heat input and thus the microstructure of the joint [1]. In a dissimilar FSW joint, where the mechanical properties and flow behavior of the two sides are significantly different, like the case of DSS and Cu-alloy, inhomogeneous material movement in the weld zone is expected. This inhomogeneous movement of material will act as a

\footnotetext{
* Corresponding author.

E-mail address: v.shokri@modares.ac.ir (V. Shokri).
} 
Table 1

Comparison of physical properties of copper and duplex stainless steel.

\begin{tabular}{llllll}
\hline & $\begin{array}{l}\text { Melting } \\
\text { point }\end{array}$ & $\begin{array}{l}\text { Thermal } \\
\text { conductivity }\end{array}$ & $\begin{array}{l}\text { Coefficient of } \\
\text { linear expansion }\end{array}$ & $\begin{array}{l}\text { Heat } \\
\text { capacity }\end{array}$ & UTS \\
\hline unit & ${ }^{\circ} \mathrm{K}$ & $\mathrm{W} / \mathrm{m}^{\circ} \mathrm{K}$ & $1 /{ }^{\circ} \mathrm{K}$ & $\mathrm{J} / \mathrm{Kg}^{\circ} \mathrm{K}$ & $\mathrm{MPa}$ \\
DSS & 1723 & 17 & $1.48 \times 10^{-5}$ & 350 & 520 \\
Cu-alloy & 1290 & 378 & $1.66 \times 10^{-5}$ & 380 & 300 \\
\hline
\end{tabular}

source of defect formation. Generally, by increasing the process temperature and feat flow, defects can be eliminated in FSW process. On the contrary, increased heat input may result in brittle and thick new phases [15].

In dissimilar FSW, formation of intermetallics at the weld interface is highly probable. The intermetallic layer increases the weld strength up to an optimum thickness. When thicker than ideal, the intermetallic layer causes brittleness and reduces strength. Sato et al. [12] have reported formation of $\mathrm{Al}_{12} \mathrm{Mg}_{17}$ intermetallic in dissimilar FSW of $\mathrm{Al}$ 1050 and Mg-AZ31. In their study, the presence of the intermetallic increased hardness at the weld center. Dehghani et al. [15] have studied $\mathrm{Al} / \mathrm{Fe}$ joints and have identified formation of different IMCs $\left(\mathrm{Al}_{5} \mathrm{Fe}_{2}\right.$ and $\left.\mathrm{Al}_{6} \mathrm{Fe}\right)$ at the weld interface and nugget. Xue et al. [17] have studied $\mathrm{Al} / \mathrm{Cu}$ joints and have reported excellent metallurgical bonding when a $1 \mu \mathrm{m}$ continuous IMC layer was formed at the interface. The identified IMC layer consisted of two $\mathrm{Al}_{2} \mathrm{Cu}$ and $\mathrm{Al}_{4} \mathrm{Cu}_{9}$ sub-layers. Zoeram et al. [20] have reported that the heat of friction leads to formation of an intermetallic layer at the joint interface of $\mathrm{Al}$ and bronze. The thickness of this IMC layer had an important role on the tensile strength of the joints. Thicker than ideal layers made the bond brittle, reduced its quality, and decreased the tensile strength.

Therefore, to obtain a uniform, defect-free joint, it is necessary to optimize various welding parameters. In the present paper, microstructures and mechanical properties of various DSS/Cu-alloy FSW butt-joints under different (1) travel speeds, (2) pin offsets, and (3) rotation rates are studied. Based on the findings, optimized process parameters and an appropriate welding window is proposed.

\section{Experimental procedure}

In order to investigate the FSW parameters of DSS and copperalloy, $4 \mathrm{~mm}$ thick hot-rolled sheets were used. Physical properties and chemical composition of DSS and copper-alloy are summarized in Tables 1 and 2 respectively.

In Fig. 1 scanning electron microscope (SEM) micrographs of the rolling direction (RD-horizontal) - Normal direction (ND-vertical) of DSS and $\mathrm{Cu}$-alloy microstructures are shown. Both microstructures feature elongated grains in the rolling direction. In Fig. 1a (DSS microstructure) the darker phase is $a$-ferrite and the brighter phase is $\gamma$-austenite.

Equilibrium phase diagrams and thermodynamic calculations were performed using Thermocalc and the TCFe7 database including, Fe, $\mathrm{Cu}, \mathrm{Cr}, \mathrm{Ni}, \mathrm{Mn}, \mathrm{Si}, \mathrm{Ti}$ and $\mathrm{C}$ in the model. Phase fractions were calculated by considering the presence of ferrite, austenite, sigma, Gphase and carbides. Fig. 2a shows the calculated equilibrium phase for DSS. Results indicate that around $400-750{ }^{\circ} \mathrm{C}$, ferrite starts to decompose to a combination of austenite and sigma. Above $800^{\circ} \mathrm{C}$ only ferrite and austenite are stable with equal fractions at $\sim 1050^{\circ} \mathrm{C}$. On the other side, for copper, all Ni-Ti intermetallics are dissolved after

Table 2

Chemical compositions of DSS and copper alloys (wt\%).

\begin{tabular}{lllllllllll}
\hline & $\mathbf{C r}$ & $\mathbf{N i}$ & $\mathbf{C}$ & $\mathbf{T i}$ & $\mathbf{P}$ & $\mathbf{S}$ & $\mathbf{S i}$ & $\mathbf{M n}$ & $\mathbf{F e}$ & $\mathbf{C u}$ \\
\hline DSS & 21 & 5 & 0.12 & 0.45 & 0.035 & 0.035 & 1 & 1 & Balance & - \\
Cu-alloy & 0.6 & 0.3 & - & 0.5 & - & - & - & - & - & Balance \\
\hline
\end{tabular}

$600{ }^{\circ} \mathrm{C}$ while Chromium particles are stable up to their melting point (Fig. 2b).

Copper alloy and DSS sheets were cut into $(300 \times 100) \mathrm{mm}$ rectangles along their rolling directions with the joining faces carefully machined to ensure right angles at the edges. Sheets were carefully degreased with acetone and dried in air prior to welding. An FSW machine capable of generating $100 \mathrm{kN}$ maximum downward force was used to join plates along their longitudinal direction (RD) (Fig. 2a). As shown in Fig. 2b, Cu-alloy and DSS sheets were positioned in retreating and advancing sides, respectively, throughout the welding process. This is mainly because when DSS with higher flow stress is located on the retreating side, penetration of the $\mathrm{Cu}$-alloy into the nugget would become very difficult. Generally, in FSW, the material on the retreating side is less intensely transported around the tool when compared with the one on the advancing side [25]. It is reported that only a portion of material transported from the leading edge undergoes chaotic flow and sound joints without defects can only be obtained when the weld interface is on the advancing side [26].

To prevent overheating on the $\mathrm{Cu}$-alloy side and reducing tool wear, the pin was inserted into the copper alloy with different offsets into the DSS plate. In this study, an offset of $0 \mathrm{~mm}$ denotes the position where the small diameter (edge) of the pin is located exactly at the weld line, and $1 \mathrm{~mm}$ is at the position where the pin side face is located at the faying surface of DSS. In Fig. 3b, the tool offset is shown on a finished joint. During the welding process, mica sheets were used beneath the two sheets to prevent sticking of the plasticized material to the anvil.

Although the effectiveness of FSW tools with multiple flats and threads have been approved for achieving seamless bonding of dissimilar materials, it is difficult to add such features for tools when joining metal pairs involving hard alloys such as steels [5]. The welding tool used in this study was made of tungsten carbide and had a $20 \mathrm{~mm}$ diameter shoulder and a conical pin, $4 \mathrm{~mm}$ long with 5 and $3 \mathrm{~mm}$ in large and small diameters, respectively. The tool and its geometry are shown in Fig. 4. The tool plunge depth and tilt angle were kept constant for all samples at $0.1 \mathrm{~mm}$ and $3^{\circ}$.

In this study, the effect of three FSW parameters on microstructure and mechanical properties of DSS/Cu-alloy joints are investigated. The three parameters are (1) Travel speed (20 and $30 \mathrm{~mm} / \mathrm{min}$ ), (b) rotation speed (1000, 1200 and $1400 \mathrm{rpm})$ and (3) tool offset $(0,0.5$ and $1 \mathrm{~mm}$ ). Maximum offset of 1 was selected based on the fact that at offsets greater than 1, significant pin wear occurred. Different studied samples at various welding conditions are listed in Fig. 5. It should be noted that the selected range of parameters is based on a large number experiments. Samples welded in conditions out of these ranges were rejected by different failures.

To investigate mechanical properties of FSW joints at various welding conditions, tensile specimens were machined out in the transverse direction so the weldment fits exactly in the center. Tensile testing was conducted according to the ASTM E8-04 standard at a strain rate of $1 \times 10^{-3} \mathrm{~s}^{-1}$. Tensile samples and their orientation in reference to the original sheet coordinate and the weld line are shown in Fig. 6.

In order to investigate microstructure evolution, samples were prepared from the weld line cross-section. Samples were ground and polished with $1 \mu \mathrm{m}$ alumina suspension in distilled water. Samples were mounted then etched using a $6 \mathrm{gr} \mathrm{FeCl}, 20 \mathrm{ml} \mathrm{HCl}, 100 \mathrm{ml}$ alcohol reagent for 20-150 s at ambient temperature. Microstructure observation was performed using optical microscopy (OM) and a scanning electron microscope (SEM) equipped with an Energy-dispersive X-ray spectroscopy (EDS) detector. X-ray diffraction (XRD) was used to examine the structure and the intermetallic layers formed in the weld zone and at the DSS/Cu-alloy interface. To make clear distinction between XRD peaks, the scan rate of was reduced and the test was prolonged $(4 \mathrm{~h})$. Micro-Vickers hardness was measured across joints with $100 \mathrm{gf}$ loading at $\sim 1 \mathrm{~mm}$ intervals. 

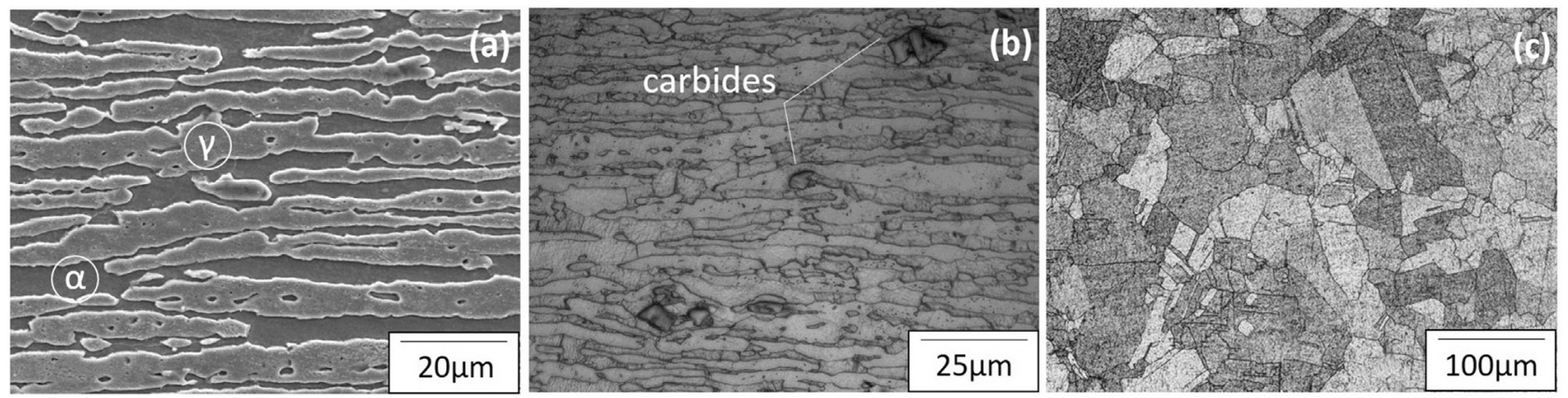

Fig. 1. Microstructures of DSS by, (a) backscattered electron detector (BSE), (b) optical microscopy and (c) copper-alloy by optical microscopy.

\section{Results and discussions}

\subsection{Microstructure}

In Fig. 7 the grain structure and material flow of sample P9 with the highest heat input among all studied samples (rotation speed: $1400 \mathrm{rpm}$, travel speed: $20 \mathrm{~mm} / \mathrm{min}$ and tool offset: $1 \mathrm{~mm}$ ) is shown. Formation of small new grains indicates that both $\mathrm{Cu}$-alloy and DSS have experienced dynamic recrystallization (DRX). Throughout the welding process, owing to the higher temperatures at the upper part of the cross-section (in contact with the shoulder) DSS moves from the advancing side (AD) towards the retreating side (RT) at the stir zone (SZ). Note that a thin layer of Cu-alloy forms on top of DSS and the lower half of the sample remains unaltered due to lower temperatures followed by higher flow stress. A higher magnification image of material movement at the stir zone is shown in Fig. 7b. The pin rotating action results in fracturing and scattering of DSS fragments and creates tiny particles in the weld zone. Vertical series of vortex rings can also be distinguished in this image. It has been reported that formation of such vortexes leads to high strength joints [5]. The thickness of sub-layer rings was measured to be $10-50 \mu \mathrm{m}$, which are comparable with the traveling distance of the welding pin per revolution (14-30 $\mu \mathrm{m} / \mathrm{rev})$ [27]. At the weld nugget (WN) extensive grain refinement has been observed. Such microstructure is common at WNs and its occurrence is previously reported. Higher magnification images of different zones of Fig. $7 \mathrm{a}$ are shown in Fig. $7 \mathrm{c}$ and $\mathrm{d}$.

In Fig. $7 \mathrm{c}$ elongation and refinement of DSS grains can be clearly seen in the thermal-mechanical affected zone (TMAZ) on the DSS side. By increasing travel speed from 20 to $30 \mathrm{~mm} / \mathrm{min}$ (sample P9 and P18) the grain size of the TMAZ zone in the DSS side decreases from 10 to $7 \mu \mathrm{m}$. On the copper side, the nugget grain size decreases from $11.2 \mu \mathrm{m}$ to $7.9 \mu \mathrm{m}$ by the same increase in travel speed. This grain size decrease is attributed to larger strain rate and smaller heat input to grow dynamic recrystallized (DRX) grains. Fig. $7 \mathrm{~d}$ shows the fine grain microstructure $(\mathrm{d}=11.2 \mu \mathrm{m})$ at the $\mathrm{Cu}$-alloy side. The copper grain size has extensively increased at the heat affected zone (HAZ) to $89.8 \mu \mathrm{m}$. However, by decreasing rotation speeds, less grain growth occurs in the DRX grains of the heat affected zone. In contrast to the Cu-alloy, microstructure of DSS is extensively pinned by different phases and alloying elements. Consequently, in the HAZ region of the DSS side, significant grain growth was not observed.

In most of the observed microstructures of different welding conditions, a different phase other than DSS and Cu-alloy could be distinguished between the two major phases. This intermetallic compound (IMC) is identified in Fig. $7 \mathrm{~b}$ as the $\sigma$-phase. Formation of $\sigma$ phase common in DSS mainly when the cooling rate from high temperatures (either in forming, welding etc.) is not fast enough. Formation of the $\sigma$-phase in the microstructure of the P9 sample is identified by the EDS peaks of Fig. 8. Sigma phase forms by partitioning of substitutional Cr (and Mo if present) [28,29]. This hard and brittle Cr-rich intermetallic results in brittleness and reduction in corrosion resistance $[30,31]$. Three distinct formation mechanisms are proposed for the $\sigma$-phase: nucleation and growth from original ferrite, eutectoid decomposition of ferrite and growth from austenite after total consumption of original ferrite [31]. Since the $\mathrm{Cr}$ concentration and diffusion rate is higher in ferrite than in austenite, the sigma precipitates from the ferrite $[28,29]$. The higher concentration of $\mathrm{Cr}$ in the steel, the higher the probability of $\sigma$-phase formation [30].
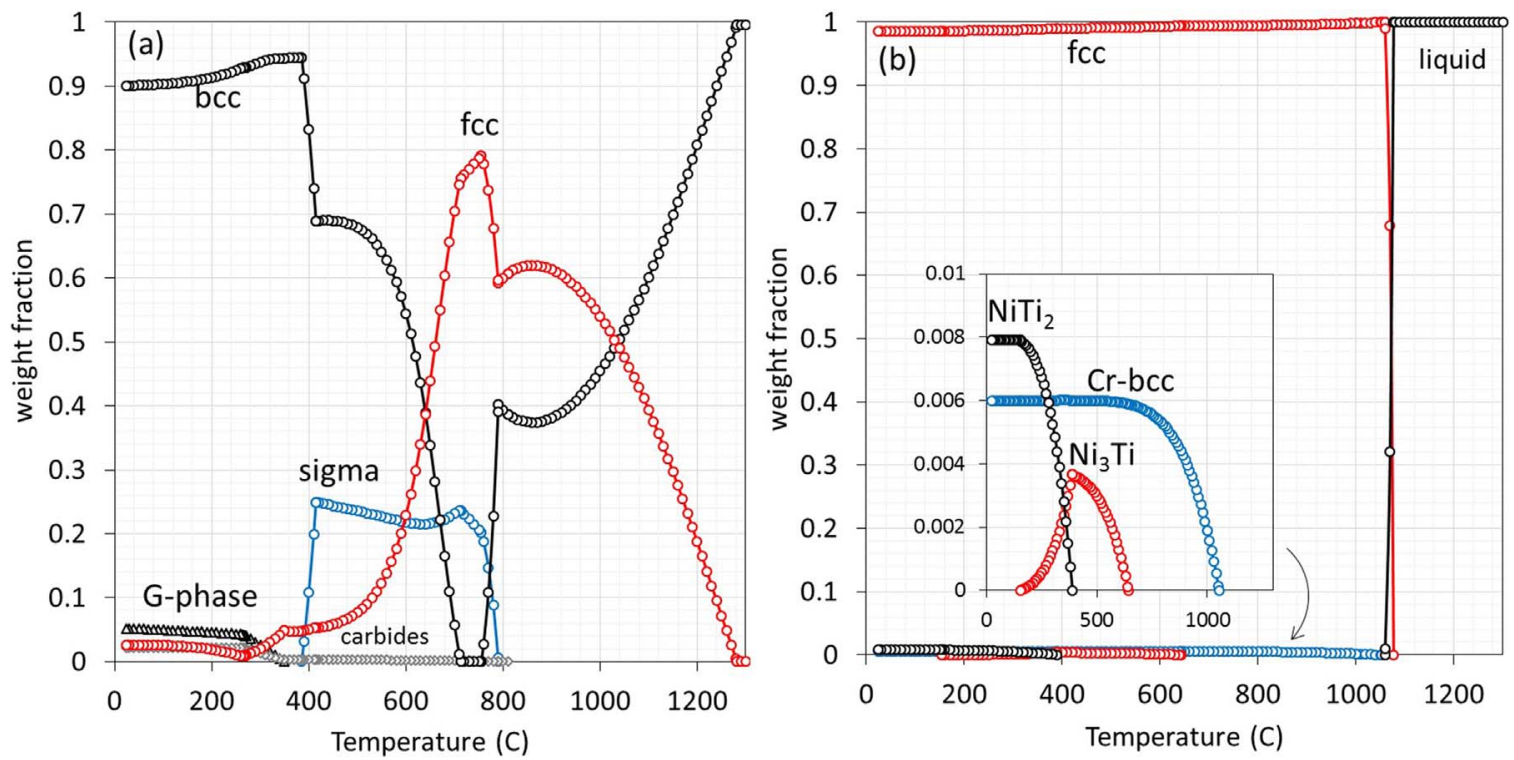

Fig. 2. Thermodynamic calculations of phase transformations of (a) DSS and (b) Cu-alloy. 

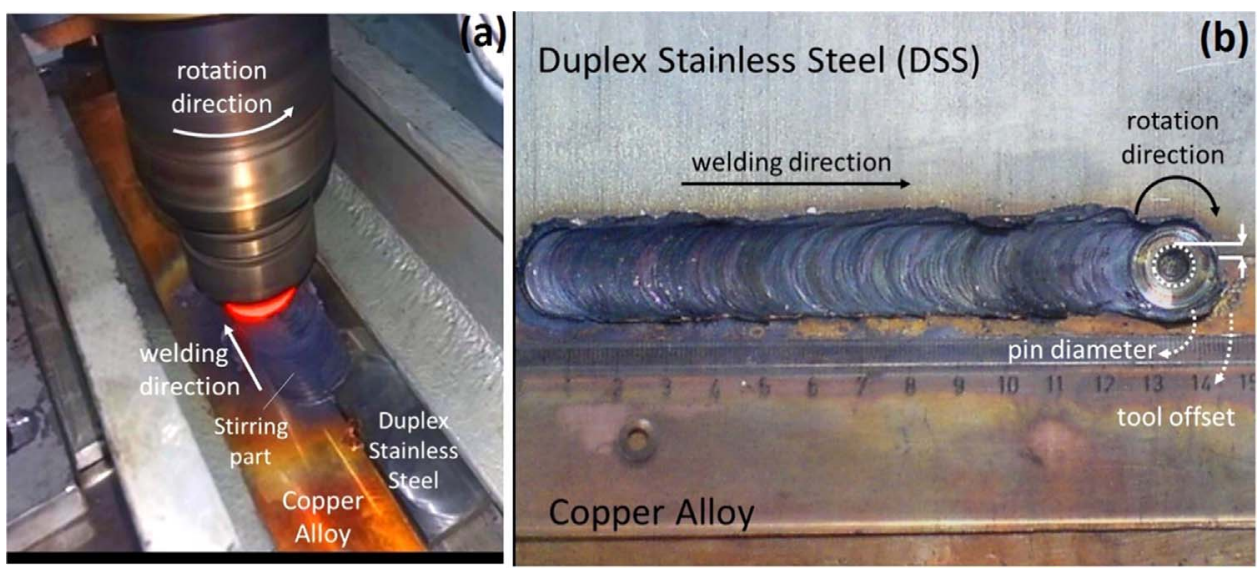

Fig. 3. (a) FSW setup configuration and (b) Tool offset, in respect to pin diameter and weld line configuration.
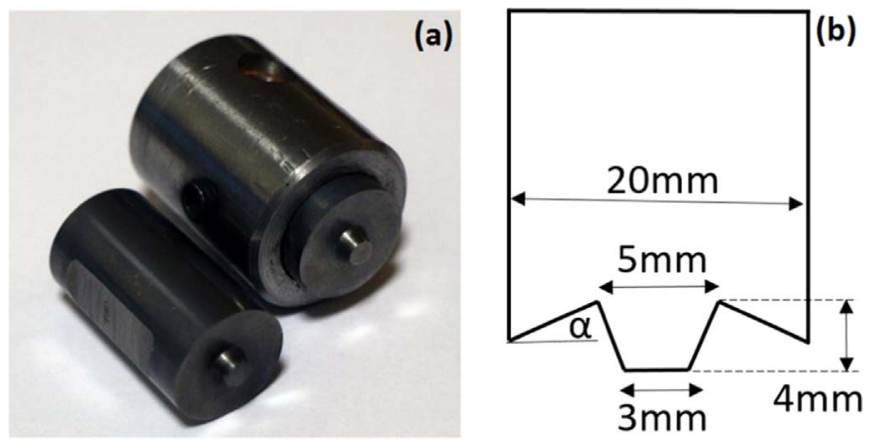

Fig. 4. (a) Tool geometry dimensions, (b) manufactured WC tool.

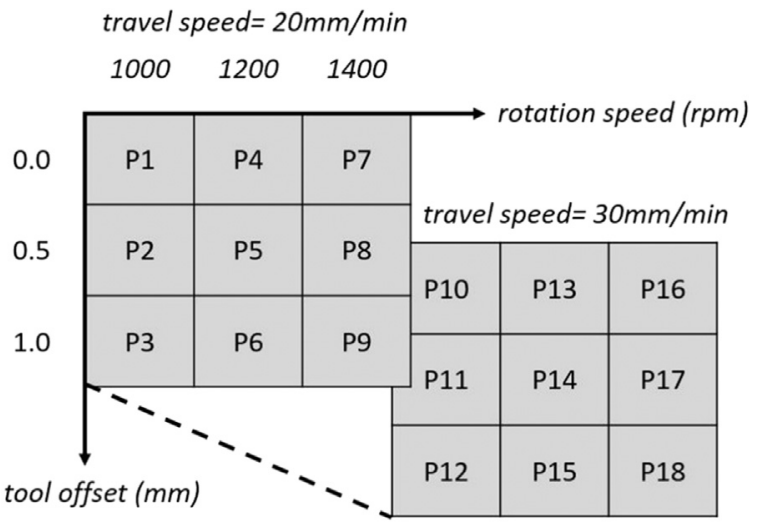

Fig. 5. Codes used for studied samples at different travel speeds, rotation speeds and tool offsets.

X-ray diffraction diagram of region A of Fig. 7 is plotted in Fig. 9. Peaks of copper, austenite and $\sigma$-phase could be clearly distinguished. Opposed to what is predicted from duplex steel joints, no peaks indicating the presence of ferrite were observed. To understand the absence of ferrite, thermodynamic calculations were performed.

To recognize thermodynamic conditions for the formation of different phases, equilibrium pseudo-binary phase diagrams of the $79 \mathrm{Fe}-21 \mathrm{Cr} / \mathrm{Cu}$ system considering different levels of $\mathrm{Ni}$ are plotted in Fig. 10a-f. Although the phase system studied in this paper only relates to the phase diagram of Fig. 10f, to have a better understanding of phase transformations, it is necessary to see the evolution of solubility lines when $\mathrm{Ni}$ concentration is gradually increased. In Fig. 10a, the phase diagram is plotted considering no $\mathrm{Ni}$ content. It can be seen that above $\sim 800^{\circ} \mathrm{C}$, only ferrite and fcc-Cu are thermodynamically stable. However, at temperatures below $\sim 600{ }^{\circ} \mathrm{C} \sigma$-phase forms at all $\mathrm{Cu}$ concentrations and austenite does not form anywhere in the phase

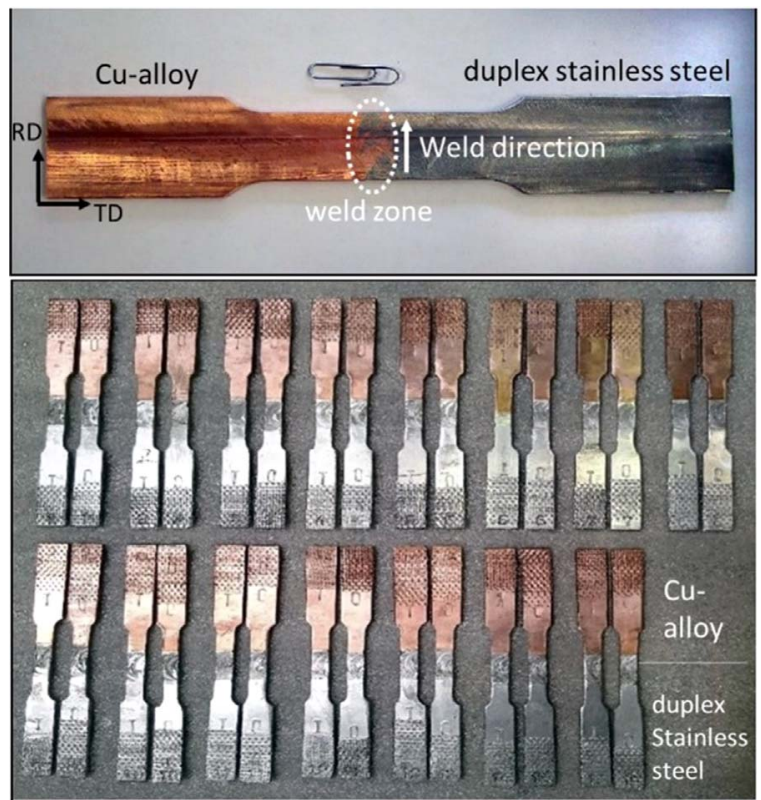

Fig. 6. Prepared tensile samples and their orientation in reference to the original sheet coordinate and the weld line.

diagram. By adding 1\% Ni (Fig. 10b) new phase fields are formed which represent temperature-composition zones which austenite is also thermodynamically stable, besides ferrite and copper. Again at low temperatures, austenite is not stable. At higher Ni concentrations, (2\%, $3 \%$, $4 \%$ and $5 \%$ in Fig. $10 \mathrm{c}-\mathrm{f}$ ), the austenite region expands and overlaps with phase fields that contain $\sigma$-phase at lower temperatures (Fig. 10f). The phase diagram presented in Fig. 10f shows that the four different ferrite, austenite, copper and $\sigma$-phase are thermodynamically stable at low temperatures. At higher $\mathrm{Cu}$ concentrations ferrite becomes unstable and again forms at very high $\mathrm{Cu}$ concentrations. It is well known that formation of the brittle $\sigma$-phase in DSS degrades mechanical and corrosion properties [23]. Therefore, the formation of this phase has been precisely measured at different FSW conditions and its effect on mechanical properties of the joint has been investigated.

In Fig. 11, the maximum thickness of the intermetallic layer has been plotted against rotation speed and tool offset at two constant travel speeds. Among the studied samples, no IMC layer was observed in the condition of $\mathrm{P} 1$ and $\mathrm{P} 10$ (minimum rotation speed and tool offset at both travel speeds). Results indicate that by increasing rotation speed and tool offset, the IMC layer thickness increases (IMC layer thickness is clearly distinguished by a different contrast using BSE detector in SEM). Although, this trend is identical for both travel 

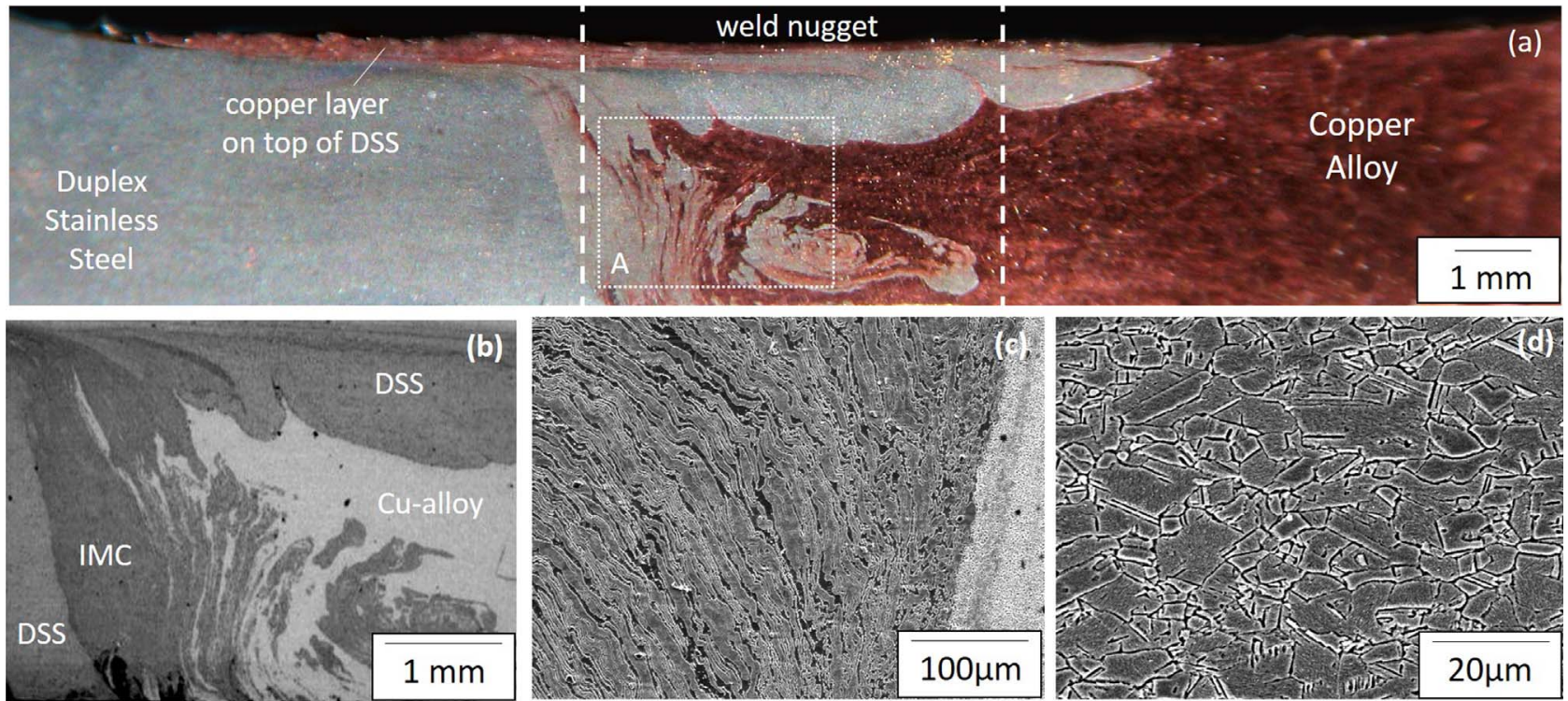

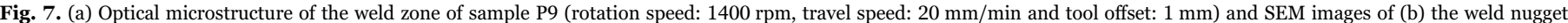
(labelled as A in a), (c) TMAZ region in DSS side and (d) the DRX zone on the copper side.

speeds, at the lower travel speed $(20 \mathrm{~mm} / \mathrm{min})$ the IMC layer grows larger. Comparing the results shows that the thickness of the formed IMC layer is directly dependent on the heat input. To investigate the relationship between the formation of the $\sigma$-phase and pressure, thermodynamic calculations have been performed.

In Fig. 12, weight percent of different thermodynamically stable phases of the DSS/Cu-alloy system is calculated against pressure (Fig. 12a) and temperature (Fig. 12b). The diagram of Fig. 12a shows that by increasing pressure, the formation of bcc-ferrite phase is restricted while fcc-austenite and sigma become more stable. This is probably due to higher packing factor of fcc $(0.74)$ and tetragonal $\sigma$ phase (0.74) compared to bcc (0.68). Since in the studied system
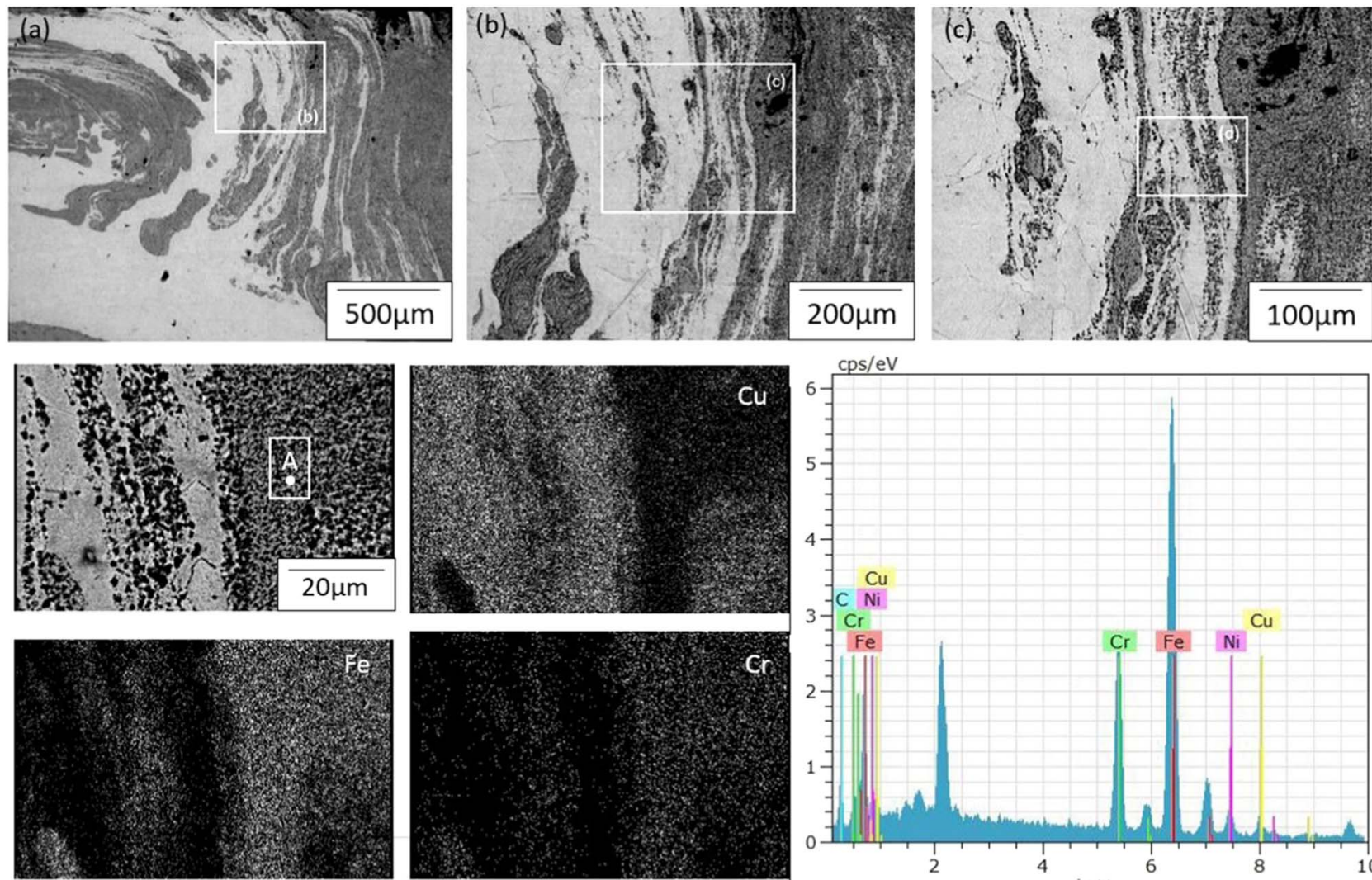

(d)

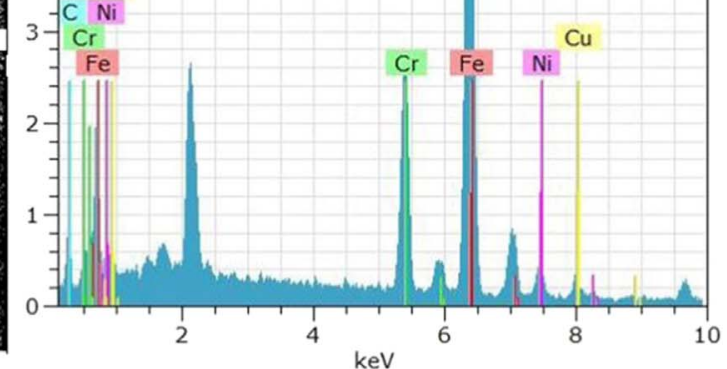

(e)

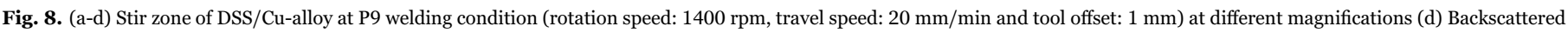

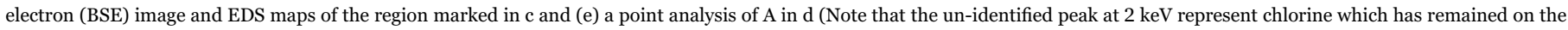
surface from etching). 


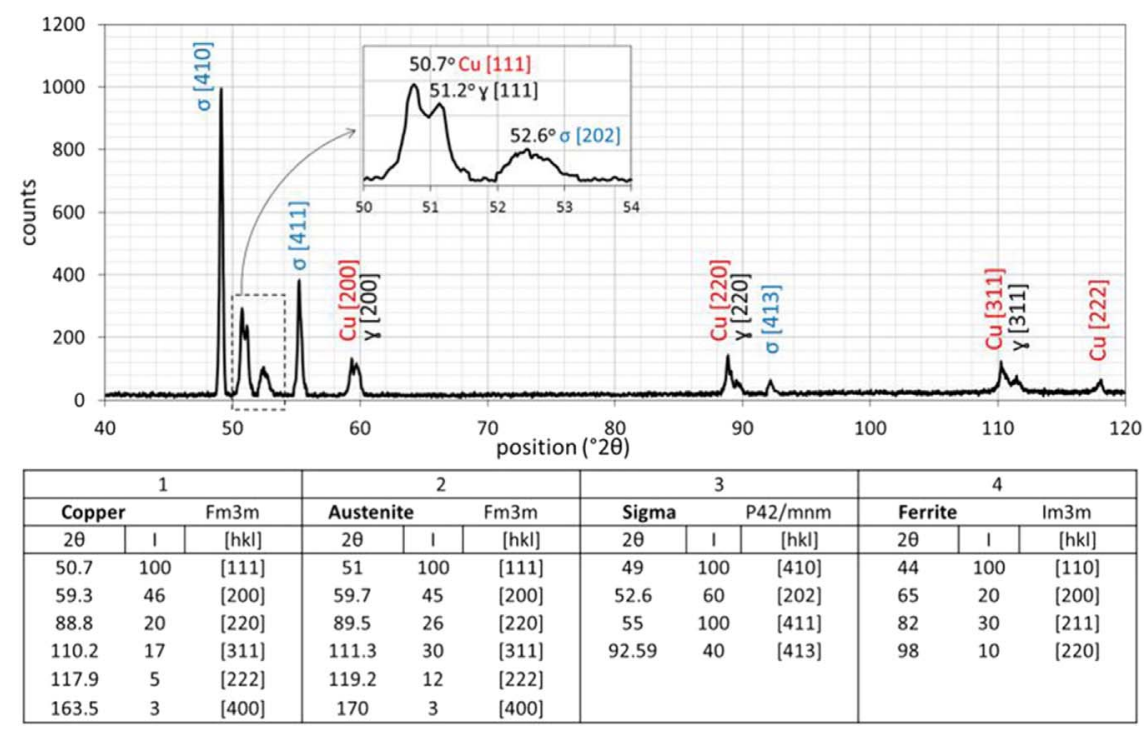

Fig. 9. X-ray diffraction peaks of region A marked in Fig. 7 along with $2 \theta$ data of possible phases.

alloying additions in copper (Ti) are not considered, no phase formation is expected in copper and its stability is not changed by pressure. Fig. 12b shows that by increasing temperature, stability of bcc-ferrite, fcc-copper and $\sigma$-phase are decreased.

Fig. $12 \mathrm{~b}$ shows that the $\sigma$-phase is only stable bellow $700{ }^{\circ} \mathrm{C}$. According to ref. [32], $\sigma$-phase morphology is strongly dependent on its formation temperature. At low temperatures (bellow $750{ }^{\circ} \mathrm{C}$, similar to the conditions studied here) coral-like structure is formed and at high precipitation temperatures, the $\sigma$-phase is more bulky. It is well accepted that mechanical properties of dissimilar FSW joints are influenced by the bonding conditions at their interface. The presence of IMCs between dissimilar metals is an indication of good metallurgical bonding. Tanaka et al. [14] showed that the bonding strength of the $\mathrm{Al}-\mathrm{Fe}$ FSW dissimilar joints is related to the thickness of the IMC layer. Although a thin, continuous and uniform IMC layer is essential for good bonding, when the IMC layer becomes too thick, poor mechanical
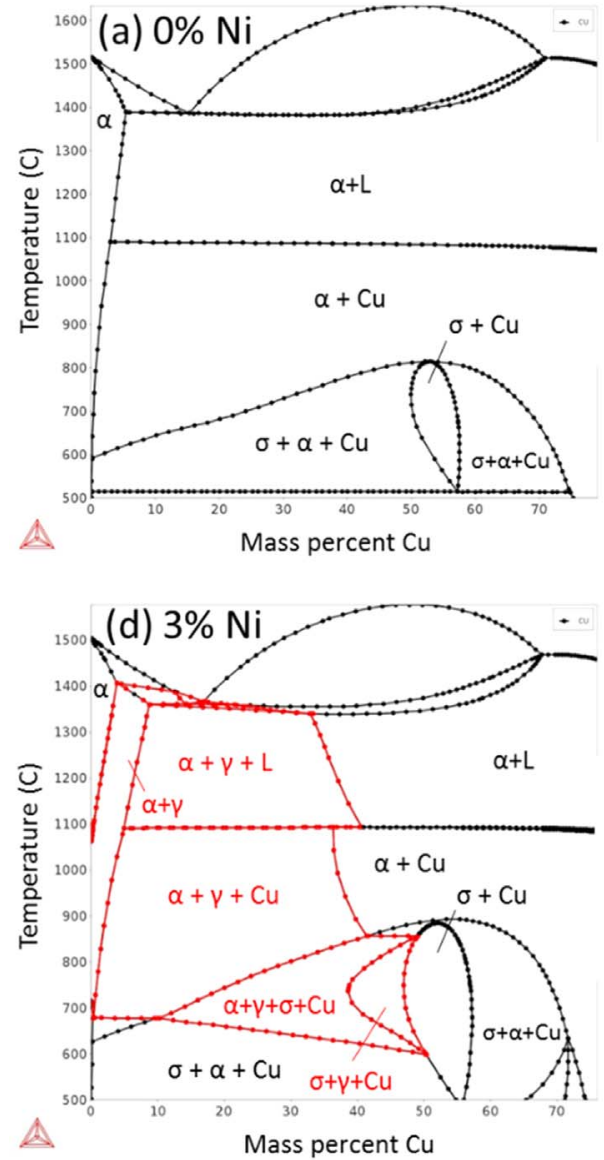
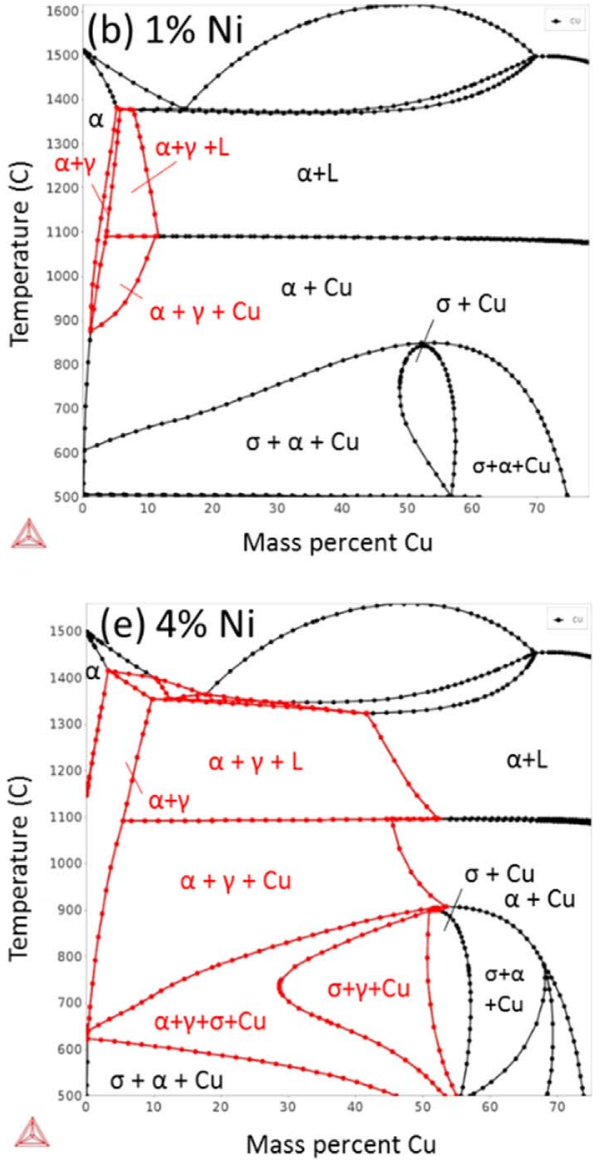
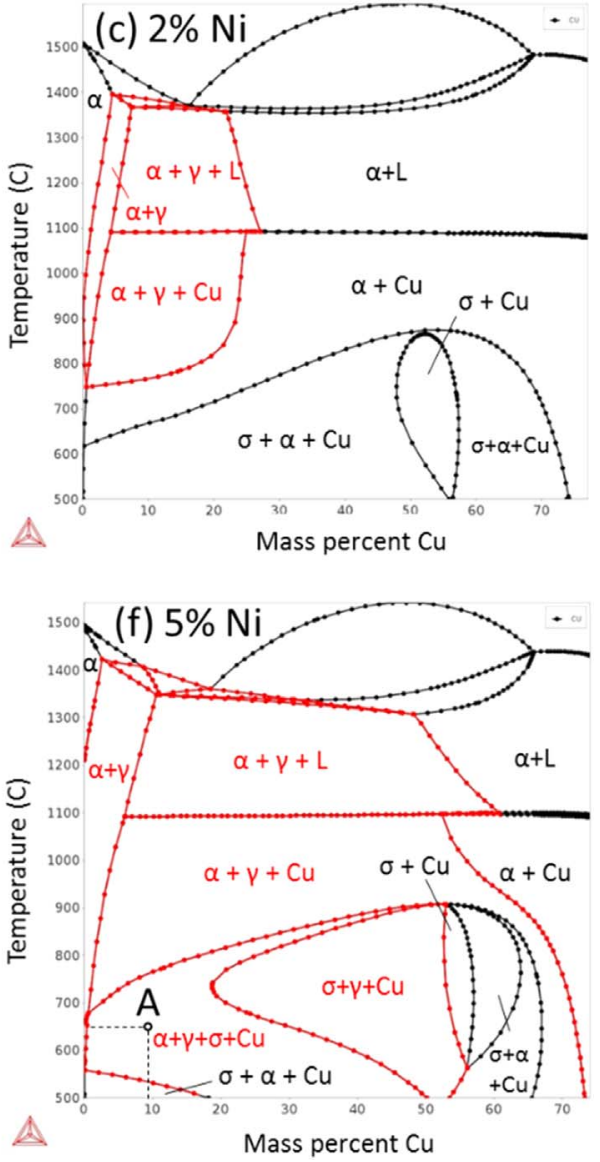

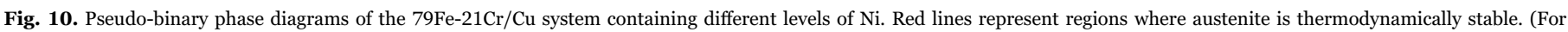
interpretation of the references to color in this figure legend, the reader is referred to the web version of this article.) 
travel speed $=20 \mathrm{~mm} / \mathrm{min}$

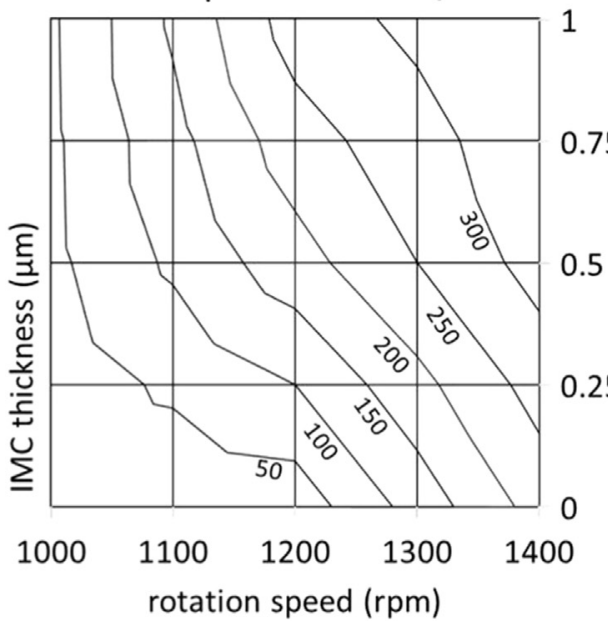

travel speed $=30 \mathrm{~mm} / \mathrm{min}$

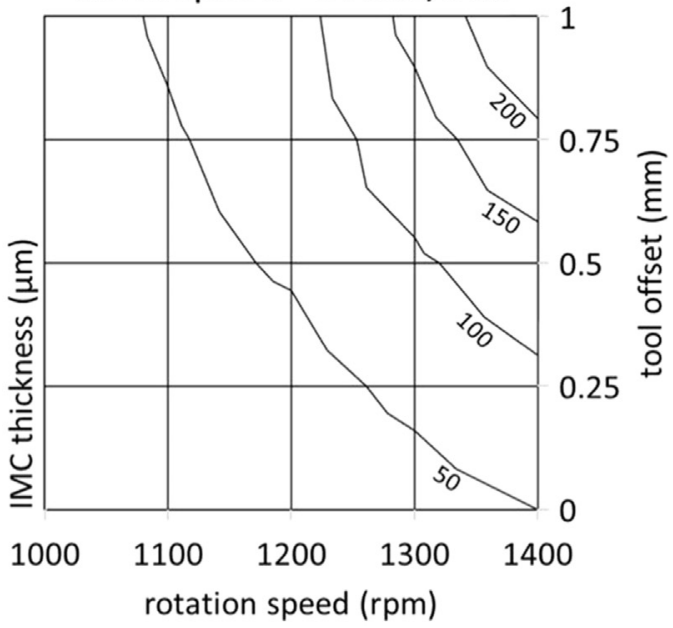

Fig. 11. Contour maps showing intermetallic layer thickness versus rotation speed and tool offset at constant travel speeds for all studied FSW conditions.

properties are expected.

Shiri et al. [33] have studied welding of copper to stainless steel by arc welding and have not observed the formation of any $\sigma$-phase at the interface. High thermal conductivity of copper was reported to be the reason why $\sigma$-phase was not formed in their samples. To understand why $\sigma$-phase is not formed in arc welding it is important to note that:

1. In arc welding, temperatures above $1000{ }^{\circ} \mathrm{C}$ are easily reached. At such welding temperatures rapid cooling formation of $\sigma$-phase is not possible [34]. While by FSW at the conditions described in this paper, the temperature must be kept below $0.8 \mathrm{~T}_{\mathrm{m}} \mathrm{Cu}\left(\sim 800{ }^{\circ} \mathrm{C}\right)$ to prevent melting of copper. These lower temperatures are more susceptible to sigma formation.

2. Compared to arc welding, in FSW, owing to the tool offset and its rotation towards the interface, less heat flux is transferred towards the copper side and the weld zone is cooled at a slower rate. Using mica plates beneath the weld interface also reduces the cooling rate. Therefore, formation of $\sigma$-phase becomes more probable.

3. As shown in Fig. 12a, high pressures applied during FSW increases the stability of $\sigma$-phase. In contrast, no pressure is applied to steel in arc welding.

\subsection{Mechanical properties}

The relation between IMC layer thickness and ultimate tensile

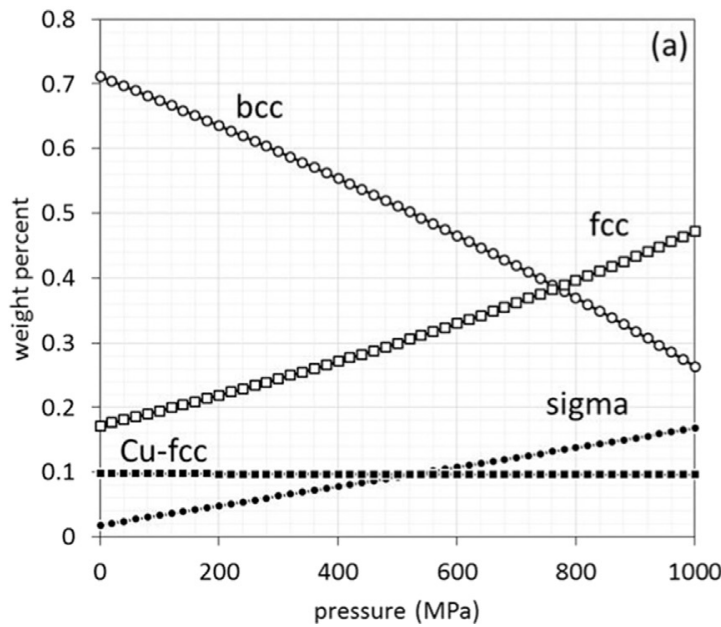

strength (UTS) of joined samples are shown in Fig. 13. The highest weld strength was achieved for the P14 sample (279 MPa), which is $96 \%$ of the UTS of the Cu-alloy. The lowest UTS was recorded for the $\mathrm{P} 1$ and P10 samples (0 and $50 \mathrm{MPa}$ ). In these two samples, the tool offset of zero and the low rotation speeds makes insufficient mixing of plasticized materials. Note that the weldment with maximum UTS was not the one having either maximum or minimum thickness of $\sigma$-phase layer (Fig. 14).

Effect of different FSW parameters on bond strength are summarized below;

- Tool offset: Results shows that at low rotation speeds, the tool offset is the key parameter in the joint strength. By increasing the tool offset from 0 to $0.5 \mathrm{~mm}$ the strength is increased from 50 to $271 \mathrm{MPa}$. This is mainly due to the fact that higher tool offsets induce more heat into the welding zone and therefore DSS pieces could react and mix more strongly with the $\mathrm{Cu}$ matrix. However at very high rotation speeds $(1400 \mathrm{rpm})$, increasing the tool offset increases the heat input more than enough and reduces the bond strength by thickening the $\sigma$-phase layer and softening the $\mathrm{Cu}$-alloy side.

- Travel Speed: In general, the travel speed of $30 \mathrm{~mm} / \mathrm{min}$ shows higher UTS compared to the travel speed of $20 \mathrm{~mm} / \mathrm{min}$. At a constant travel speed of $20 \mathrm{~mm} / \mathrm{min}$, the UTS increases with the decrease of rotation speed.

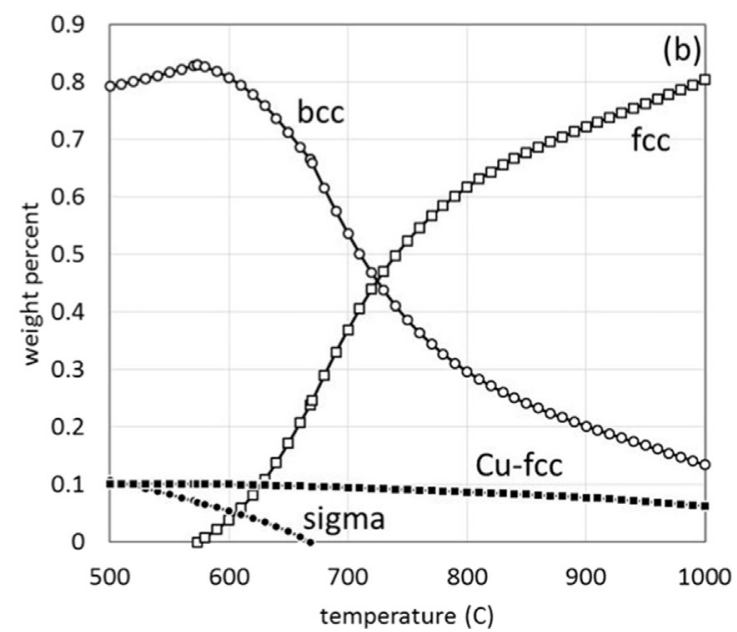

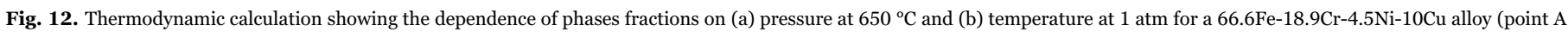
in Fig. 10f). 


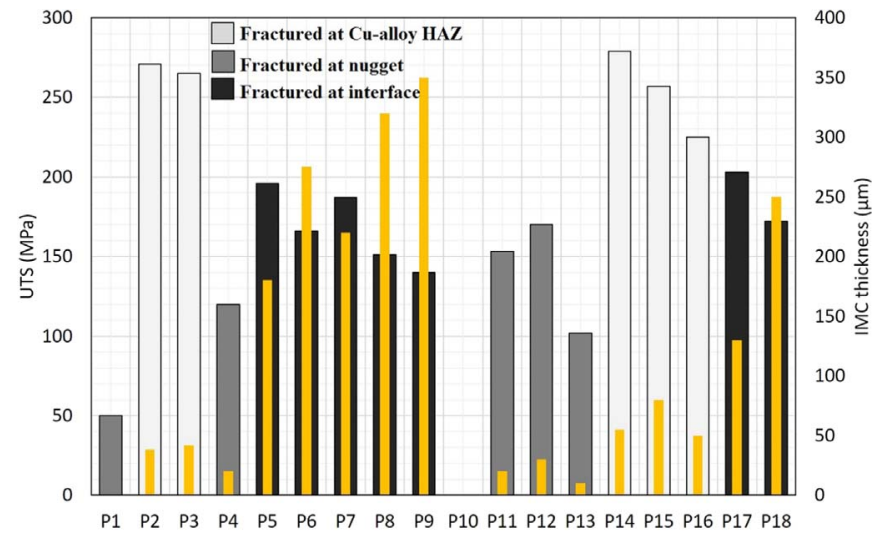

Fig. 13. Ultimate tensile strength and IMC thickness (narrow columns) of welded samples at different FSW conditions. Columns are labelled based on the location of fracture in regard to the weld line.

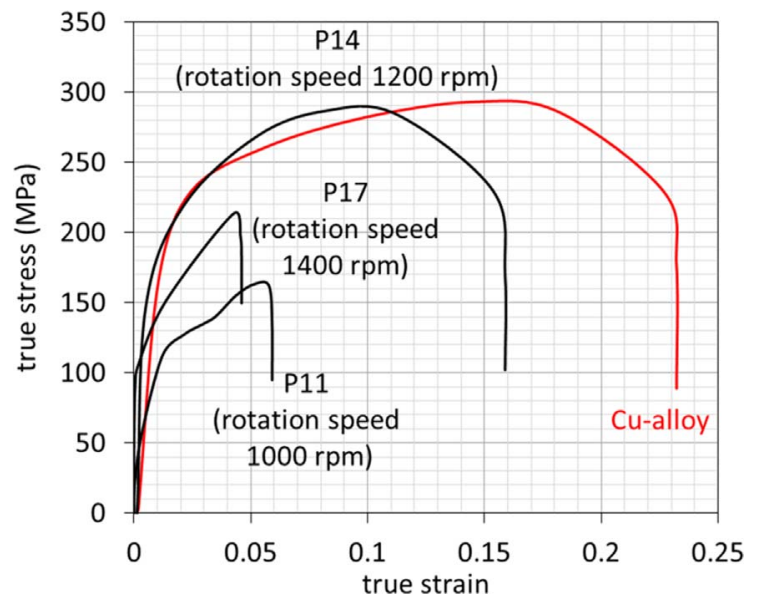

Fig. 14. True stress - true strain curves of joints performed at the travel speed of $30 \mathrm{~mm} / \mathrm{min}, 0.5 \mathrm{~mm}$ tool offset and at different rotation speeds compared to that of $\mathrm{Cu}-$ alloy.

- Rotation speed: At low tool offsets, increasing rotation speed prepares a better bond and increases strength. In contrast, at high tool offsets, increasing rotation speed reduces the bond strength by softening. At intermediate tool offset $(0.5 \mathrm{~mm})$ there is an optimum rotation speed which results in the highest mechanical properties. In Fig. 1 three true stress - true strain curves of three FSW samples processed at different rotation speeds (other parameters are constant) are compared with that of $\mathrm{Cu}$-alloy. It can be seen that the

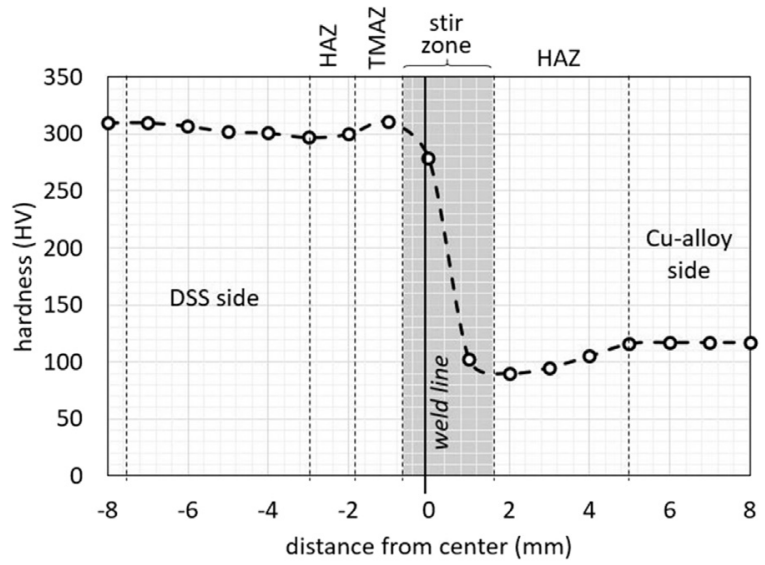

Fig. 16. Micro-Vickers hardness profile across the weld line measured on the centreline perpendicular to the welding direction for the P14 sample.

sample processed at $1200 \mathrm{rpm}$ has the highest tensile strength. The fact that the work hardening rate is very close to $\mathrm{Cu}$-alloy shows that failure and deformation are localized on the copper side.

By comparing the samples strength and the IMC layer thickness of Fig. 13, a relation between IMC layer thickness and fracture mode can be drawn. It can be seen that at high IMC layer thicknesses, fracture occurs at the interface line; when the IMC thickness is small, samples break at the weld nugget. Highest tensile strengths were observed in samples with the intermediate thickness of IMC layer which the fracture occurs at the $\mathrm{Cu}$-alloy side (the HAZ region). Fig. 15 shows different modes of brittle fracture at the interface (sample P9) and ductile fracture at the $\mathrm{Cu}$-alloy side (sample $\mathrm{P} 14$ ).

The interface of samples which fractured at the seam (P5-9, P17 and P18) do not exhibit significant development of a localized necking and comparatively show less strength. However, in the welding conditions were the fracture has occurred on the copper side (P2, P3, P14, P15 and P16 samples) the weldment presented higher strength. To understand the source of failure in samples with ductile fracture at the $\mathrm{Cu}$-side, Vickers micro-hardness profiles were plotted along the center line of the transverse cross section (P14 sample in Fig. 16). The hardness profile clearly shows a decrease in hardness at the HAZ zone of the $\mathrm{Cu}$-alloy side. This is mainly because of the coarsening of precipitates and grain growth caused by FSW thermal cycle. In contrast to the samples fracturing at the weld interface, fracture in the $\mathrm{Cu}$-alloy side is caused by softening, and involves the significant development of localized necking.

It is known that $\sigma$-phase increases the ultimate strength of DSS
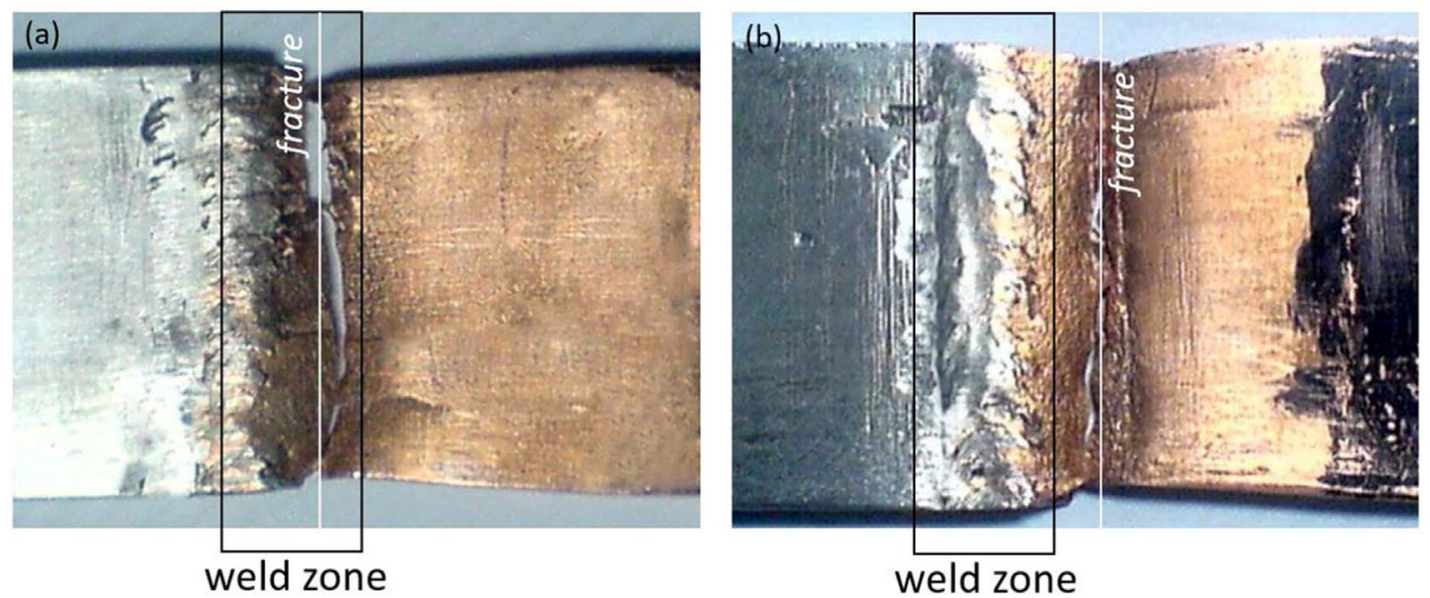

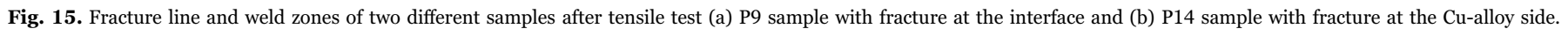



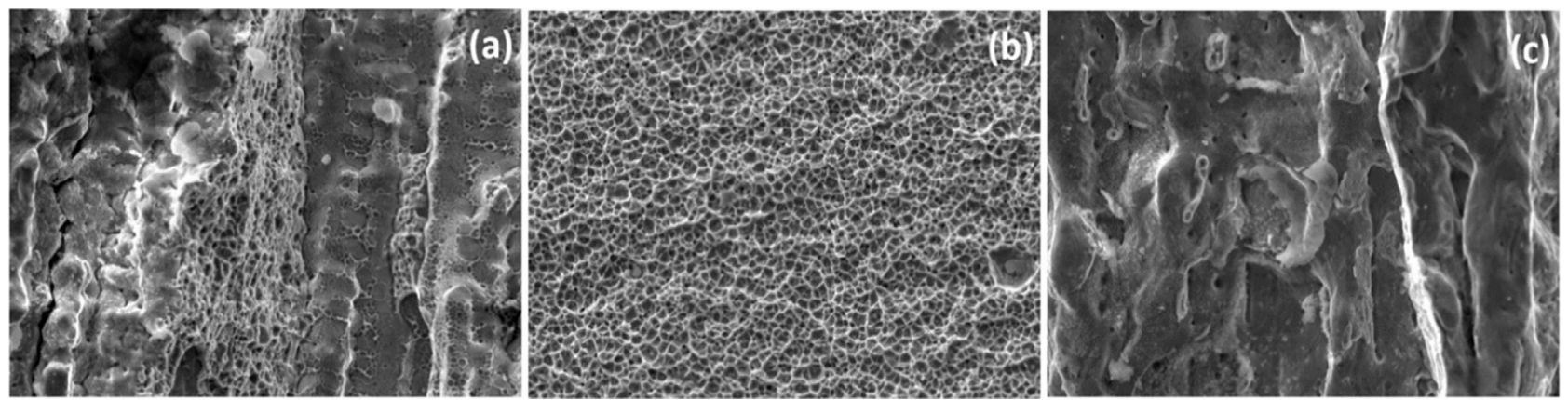

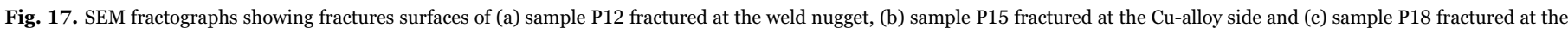
interface.

[32]. However in the studied samples, in the optimum conditions of sigma formation, copper has lost its strength due to work softening and samples eventually fail at their copper side. In the samples were the $\sigma$ phase is thick, strength gradient causes stress concentration and fracture at the sigma rich interface.

\subsection{Fracture surface}

In Fig. 17 fracture surfaces of three samples with constant travel speed and tool offset $(30 \mathrm{~mm} / \mathrm{min}$ and $1 \mathrm{~mm}$, respectively) and rotation speeds of 1000,1200 and $1400 \mathrm{rpm}$ are shown (samples P12, P15 and P8). In Fig. 17a a combination of dimples, tearing edges and cleavage-like features are evident in the fracture surface. As previously indicated in Fig. 13, this sample (P12) has fractured at the weld nugget. In this sample mixing was not enough and the mechanical and metallurgical bonding is insufficient. The existence of both DSS and $\mathrm{Cu}$-alloy at the weld nugget is why both ductile and brittle features are formed in the fracture surface.

The sample having the intermediate rotation speed $(1200 \mathrm{rpm}$, sample $\mathrm{P} 15$ ) has fractured at the $\mathrm{Cu}$-alloy side and its fracture surface is entirely covered by dimples which indicate ductile fracture (Fig. 17b). On the contrary, the final sample with the highest rotation speed (1400 rpm, sample 18) and the highest IMC thickness which has fractured at its weld line and shows facet-like structures, representing a brittle fracture (Fig. 17c).

Comparing the fracture modes and FSW parameters it is concluded that the samples with low heat input and insufficient material mixing fracture at the weld nugget in a mixed ductile-brittle mode. In contrast, at highest heat inputs, IMC-layer thickens and the brittle phase weakens the interface and a total brittle fracture occurs at the interface [23]. Nevertheless, there is an optimum heat input range were sufficient material steering reinforces the nugget and enough IMC strengthens the weld interface. In such conditions, the weld fails at the softest section which is the $\mathrm{HAZ}$ zone at the $\mathrm{Cu}$-alloy side. In this region high temperatures increase the grain size and weaken the material.

\section{Conclusions}

In the present study, the effect of friction stir welding parameters (rotation speed, travel speed and tool offset) on microstructural and mechanical properties of joined duplex stainless steel (DSS) and a copper alloy was investigated. It has been found that the hard and brittle $\sigma$-phase intermetallic forms at the welded interface and its thickness is directly dependent on the heat input. At the weld zone, high concentrations of copper and high pressure prevent the formation of $\alpha$-ferrite at the weld interface. Welding quality was found to be poor at low heat inputs where insufficient plasticizing and mixing occurs. While at very high heat inputs, samples show low mechanical properties due to the formation of a thick $\sigma$-phase layer which concentrates stress at the weld line. There is an optimum intermetallic layer thickness $(55 \mu \mathrm{m})$ which results in the highest ultimate tensile strength
(279 MPa). The highest joint strength was obtained using the rotation speed of $1200 \mathrm{rpm}$, the travel speed of $30 \mathrm{~mm} / \mathrm{min}$ and tool offset of $0.5 \mathrm{~mm}$.

\section{Acknowledgement}

The authors would like to acknowledge the funding for this project from the Iran National Science Foundation (INSF) (95849272).

\section{References}

[1] T. DebRoy, H.K.D.H. Bhadeshia, Friction stir welding of dissimilar alloys - a perspective, Sci. Technol. Weld. Join. 15 (4) (2013) 266-270.

[2] J. Guo, P. Gougeon, X.G. Chen, Microstructure evolution and mechanical properties of dissimilar friction stir welded joints between AA1100-B 4 C MMC and AA6063 alloy, Mater. Sci. Eng.: A 553 (2012) 149-156.

[3] L.E. Murr, A review of FSW research on dissimilar metal and alloy systems, J. Mater. Eng. Perform. 19 (8) (2010) 1071-1089.

[4] P.L. Thredgill, A.J. Leonard, H.R. Shercliff, P.J. Withers, Friction stir welding of aluminium alloys, Int. Mater. 54 (2009) 49-93.

[5] J.F. Guo, H.C. Chen, C.N. Sun, G. Bi, Z. Sun, J. Wei, Friction stir welding of dissimilar materials between AA6061 and AA7075 Al alloys effects of process parameters, Mater. Des. 56 (2014) 185-192.

[6] P. Motalleb-nejad, T. Saeid, A. Heidarzadeh, Kh Darzi, M. Ashjari, Effect of tool pin profile on microstructure and mechanical properties of friction stir welded AZ31B magnesium alloy, Mater. Des. 59 (2014) 221-226.

[7] Shude Ji, Zhengwei Li, Yue Wang, Lin Ma, Joint formation and mechanical properties of back heating assisted friction stir welded Ti-6Al-4V alloy, Mater. Des. 113 (2017) 37-46.

[8] Jamal Teimournezhad, Abolfazl Masoumi, Experimental investigation of onion ring structure formation in friction stir butt welds of copper plates produced by non threaded tool pin, Sci. Technol. Weld. Join. 15 (2) (2009) 166-170.

[9] S. Karami, H. Jafarian, A.R. Eivani, S. Kheirandish, Engineering tensile properties by controlling welding parameters and microstructure in a mild steel processed by friction stir welding, Mater. Sci. Eng.: A 670 (2016) 68-74.

[10] H.K. Sharma, K. Bhatt, K. Shah, U. Joshi, Experimental analysis of friction stir welding of dissimilar alloys AA6061 and Mg AZ31 using circular butt joint geometry, Procedia Technol. 23 (2016) 566-572.

[11] R. Zettler, A.A.M. Da Silva, S. Rodrigues, A. Blanco, J.F. Dos Santos, Dissimilar Al to Mg alloy friction stir welds, Adv. Eng. Mater. 8 (5) (2006) 415-421.

[12] Y.S. Sato, S.H.C. Park, M. Michiuchi, H. Kokawa, Constitutional liquation during dissimilar friction stir welding of $\mathrm{Al}$ and Mg alloys, Scr. Mater. 50 (9) (2004) 1233-1236.

[13] T. Watanabe, H. Takayama, A. Yanagisawa, Joining of aluminum alloy to steel by friction stir welding, J. Mater. Process. Technol. 178 (1) (2006) 342-349.

[14] T. Tanaka, T. Morishige, T. Hirata, Comprehensive analysis of joint strength for dissimilar friction stir welds of mild steel to aluminum alloys, Scr. Mater. 61 (7) (2009) 756-759.

[15] M. Dehghani, A. Amadeh, S.A. Mousavi, Investigations on the effects of friction stir welding parameters on intermetallic and defect formation in joining aluminum alloy to mild steel, Mater. Des. 49 (2013) 433-441.

[16] J. Ouyang, E. Yarrapareddy, R. Kovacevic, Microstructural evolution in the friction stir welded 6061 aluminum alloy (T6-temper condition) to copper, J. Mater. Process. Technol. 172 (1) (2006) 110-122.

[17] P. Xue, B.L. Xiao, D.R. Ni, Z.Y. Ma, Enhanced mechanical properties of friction stir welded dissimilar Al-Cu joint by intermetallic compounds, Mater. Sci. Eng.: A 527 (21) (2010) 5723-5727.

[18] T. Saeid, A. Abdollah-Zadeh, B. Sazgari, Weldability and mechanical properties of dissimilar aluminum-copper lap joints made by friction stir welding, J. Alloy. Compd. 490 (1) (2010) 652-655.

[19] P. Liu, Q. Shi, W. Wang, X. Wang, Z. Zhang, Microstructure and XRD analysis of FSW joints for copper T2/aluminium 5A06 dissimilar materials, Mater. Lett. 62 (25) (2008) 4106-4108 
[20] A.S. Zoeram, S.M. Anijdan, H.R. Jafarian, T. Bhattacharjee, Welding parameters analysis and microstructural evolution of dissimilar joints in $\mathrm{Al} /$ Bronze processed by friction stir welding and their effect on engineering tensile behavior, Mater. Sci. Eng.: A 687 (2017) 288-297.

[21] B.P. Logan, A.I. Toumpis, A.M. Galloway, N.A. McPherson, S.J. Hambling, Dissimilar friction stir welding of duplex stainless steel to low alloy structural steel, Sci. Technol. Weld. Join. 21 (1) (2016) 11-19.

[22] C.C. Hsieh, W. Wu, Overview of Intermetallic Sigma $(\sigma)$ Phase Precipitation in Stainless Steels, ISRN Metall. 2012 (2012).

[23] Riad Badji, et al., Phase transformation and mechanical behavior in annealed 2205 duplex stainless steel welds, Mater. Charact. 59 (4) (2008) 447-453.

[24] Osman Yilmaz, Mustafa Aksoy, Investigation of micro-crack occurrence conditions in diffusion bonded Cu-304 stainless steel couple, J. Mater. Process. Technol. 121 (1) (2002) 136-142.

[25] S.-K. Park, S.-T. Hong, J.-H. Park, K.-Y. Park, Y.-J. Kwon, H.-J. Son, Effect of material locations on properties of friction stir welding joints of dissimilar aluminium alloys, Sci. Technol. Weld. Join. 15 (4) (2010) 331-336.

[26] K. Kumar, S.V. Kailas, Positional dependence of material flow in friction sti welding: analysis of joint line remnant and its relevance to dissimilar metal welding, Sci. Technol. Weld. Join. 15 (2010) 305-311.
[27] R.S. Mishra, Z.Y. Ma, Friction stir welding and processing, Mater. Sci. Eng.: R: Rep. 50 (1) (2005) 1-78

[28] T.H. Chen, J.R. Yang, Effects of solution treatment and continuous cooling on $\sigma-$ phase precipitation in a 2205 duplex stainless steel, Mater. Sci. Eng.: A, 311(1), pp $28-41$.

[29] L. Duprez, B.C. De Cooman, N. Akdut, Redistribution of the substitutional elements during $\sigma$ and X phase formation in a duplex stainless steel, Steel Res. 72 (8) (2001) $311-316$.

[30] M.B. Cortie, E.M.L.E.M. Jackson, Simulation of the precipitation of $\sigma$-phase in duplex stainless steels, Metall. Mater. Trans. A 28 (12) (1997) 2477-2484.

[31] R. Magnabosco, Kinetics of $\sigma$-phase formation in a duplex stainless steel, Mater. Res. 12 (3) (2009) 321-327.

[32] M. Pohl, O. Storz, T. Glogowski, Effect of intermetallic precipitations on the properties of duplex stainless steel, Mater. Charact. 58 (1) (2007) 65-71.

[33] S.G. Shiri, M. Nazarzadeh, M. Sharifitabar, M.S. Afarani, Gas tungsten arc welding of CP-copper to 304 stainless steel using different filler materials, Trans. Nonferrous Met. Soc. China 22 (12) (2012) 2937-2942.

[34] M.E. Wilms, V.J. Gadgil, J.M. Krougman, F.P. Ijsseling, The effect of $\sigma$-phase precipitation at $800{ }^{\circ} \mathrm{C}$ on the corrosion resistance in sea-water of a high alloyed duplex stainless steel, Corros. Sci. 36 (5) (1994) 871877-875881. 